\title{
Kan apolipoprotein-nivåer målt fra opptinte blodprøver etter 12-14 års nedfrysing brukes for epidemiologiske formål? En pilotanalyse av HUNT 2-data
}

\author{
Ingar Holme ${ }^{1,5}$, Bjarte Storaas ${ }^{2}$, Kristian Bjerve ${ }^{3}$, Arne T. Høstmark ${ }^{4,5}$ og Jostein Holmen ${ }^{6}$ \\ 1) Oslo Universitetssykehus HF, Ullevål sykehus, avdeling for forebyggende medisin, seksjon for \\ preventiv kardiologi, Oslo \\ 2) Nøste legekontor, Lier, Universitetet i Oslo, Institutt for allmenn-og samfunnsmedisin/seksjon for \\ forebyggende medisin- og epidemiologi \\ 3) St Olavs hospital, laboratorium for klinisk kjemi, Trondheim \\ 4) Universitetet i Oslo, Institutt for helse og samfunn, Seksjon for forebyggende medisin- og epidemiologi \\ 5) Norges Idrettshøyskole, Seksjon for idrettsmedisinske fag, Oslo \\ 6) HUNT forskningssenter, Institutt for samfunnsmedisin, Det medisinske fakultet, NTNU, Levanger \\ Korrespondanse: Ingar Holme, Oslo Universitetssykehus HF, Ullevål sykehus, avdeling for forebyggende medisin, seksjon for preventiv \\ kardiologi, Postboks 4956 Nydalen, 0424 Oslo \\ e-post: ingar.holme@uus.noＴelefon: +4722117927/+4791325542(Mob) Telefax: +4722119975
}

\begin{abstract}
SAMMENDRAG
I Norge er det lagret store mengder nedfrosne blodprøver fra helseundersøkelser av ulike slag. Stabilitet av målinger av apolipoproteiner fra langtids nedfrosne blodprøver er lite dokumentert.

Ny forståelse av lipoproteinenes fysiologi og betydning for utvikling av ateromatose reiser spørsmålet om andre lipoproteinkomponenter enn total (TC), LDL (LDL-C) og HDL-kolesterol (HDL-C) bør vurderes som risikomarkører. Ikke minst gjelder dette apolipoproteinene og balansen mellom apolipoprotein B (apoB) og apolipoprotein A-1 (apoA-1). Nedfrosne blodprøver kunne kanskje anvendes til å analysere sammenheng mellom nivåer på apolipoproteiner og utvikling av kardiovaskulære hendelser, hvis det ikke har skjedd vesentlige konsentrasjonsforandringer under lagring. For å undersøke dette ble det foretatt en pilotstudie av blodprøver fra 300 personer i HUNT 2. For disse hadde en ferske blodprøver, og i 2009 opptinte blodprøvemålinger av lipoproteiner samt apoB og apo A-1. Disse har bare vært lagret ved $-40{ }^{\circ} \mathrm{C}$.

Resultatene viste at TC var øket med $0,3 \mathrm{mmol} / \mathrm{L}$ fra fersk til smeltet tilstand til tross for at HDL-C var blitt redusert med 0,25 mmol/L. Korrelasjonene mellom ferske og opptinte prøver var høye $(0,93-0,99)$. Variasjonskoeffisientene var derimot høye $(5,8-13,7 \%)$ og endringene var nivåavhengige. Nivåene på apolipoproteinene var klart høyere, mens apoB/apoA-1 ratio samsvarte mer med andre studierapporter. Korrelasjonene mellom apo-og lipoproteiner var på et nivå man gjenfinner i andre studier.

Resultatene må tolkes som bare indikative på at apolipoproteiner, og da spesielt ratio apoB/apoA-1, kan brukes i HUNT 2 til prognostiske studier av kardiovaskulære hendelser og død. Hoveddelen av HUNT 2 biobank har imidlertid ligget i ro i $-80^{\circ} \mathrm{C}$ og lipoproteiner endres neppe ved denne temperatur. Prognostiske studier med apolipoproteiner som prediktorer burde derfor med rimelig sikkerhet kunne utføres i HUNT 2. Endelig bevis for dette kan imidlertid først oppnås når slike opptinte prøver blir analysert.
\end{abstract}

Holme I, Storaas B, Bjerve K, Høstmark AT, Holmen J. Can frozen and thawed blood samples stored for 12-14 years be used to measure levels of apolipoproteins? Analysis from HUNT 2 data. Nor J Epidemiol 2010; 20 (1): 125-130.

\section{ENGLISH SUMMARY}

In Norway, large numbers of frozen blood samples from health surveys are stored in freezers at -70 to $-80^{\circ} \mathrm{C}$. An assumption has been that levels of lipoproteins (total cholesterol (TC), low-density lipoprotein cholesterol (LDL-C), high-density lipoprotein cholesterol (HDL-C) and triglycerides (TG)) have been kept at constant levels during long-term storage. The stability of long-term storage of apolipoproteins is weakly documented.

The Health Survey of Nord-Trøndelag in 1995-97 (HUNT 2) provides the possibility to analyse relationships between levels of lipoproteins and incident cardiovascular disease. A project group consisting of the present authors questioned whether use of apolipoproteins as risk markers may give at least as good predictive value as the traditional lipoproteins and whether the frozen samples in HUNT 2 can be used for this purpose. To investigate this issue a pilot study based on 300 thawed blood samples from HUNT 2 was performed. For these subjects lipoprotein levels measured at screening in 1995-97 were available as well as the same levels from the thawed samples including also apolipoprotein B (apoB) and apolipoprotein A-1 (apoA-1). For special reasons these samples had only been frozen down to $-40{ }^{\circ} \mathrm{C}$. 
Results showed that TC was increased by $0.3 \mathrm{mmol} / \mathrm{l}$ from fresh to thawed state during these years, despite that HDL-C had been reduced by $0.25 \mathrm{mmol} / \mathrm{L}$. The correlations between fresh and thawed lipoprotein levels were high $(\mathrm{r}=0.93-0.99)$. However, coefficients of variation were high $(\mathrm{CV}=5.8-13.7 \%)$ and changes were dependent on the level. The levels of apolipoproteins were clearly elevated, especially apoA-1, as compared to other similar populations. Though, apoB/apoA-1 coincided better with reported levels from elsewhere. Correlations between apo -and lipoproteins were at similar magnitudes as reported from other studies.

These results only indicate that apolipoproteins, especially apoB/apoA-1 ratio, may be used in prognostic studies in HUNT 2. However, the major bulk of the HUNT 2 biobank has been kept frozen and without disturbances at $-80^{\circ} \mathrm{C}$. At this temperature there is agreement that levels of lipoproteins are kept stable. It is therefore fair to conclude that prognostic studies of once thawed apolipoprotein levels from $-80{ }^{\circ} \mathrm{C}$ should provide valid relational estimates. However, final proof of this can not be given until thawed samples from this pool is analysed.

\section{INNLEDNING}

I Norge er det i de senere tiår blitt lagret store mengder frosne blodprøver fra helseundersøkelser av mange slag. Disse har vanligvis blitt frosset til -70 eller -80 ${ }^{\circ} \mathrm{C}$. Målinger av lipoprotein-konsentrasjoner som total kolesterol (TC), LDL-C ("low density lipoprotein cholesterol"), HDL-C ("high density lipoprotein cholesterol”) og triglyserider (TG) har vært antatt å være stabile under slike forhold. Det er likevel kjent at dess lavere lagringstemperatur, dess mindre aktivitet er det i blodprøvene (1). Validiteten av apolipoproteinmålinger etter langvarig nedfrysing er lite dokumentert. Ved den andre Helseundersøkelsen i Nord-Trøndelag (HUNT 2) ble det i 1995-97 frosset ned blod (fullblod og serum) til $-80^{\circ} \mathrm{C}(2)$. Et stort antall serumprøver av de samme personene ble dessuten lagret ved $-40{ }^{\circ} \mathrm{C}$. Grunnet knapphet på biobankmaterialet nedfrosset til $-80{ }^{\circ} \mathrm{C}$, ble det reist spørsmål om disse prøvene kan brukes til å måle apolipoproteinnivåer etter 12-14 års lagring. Hvis dette kan dokumenteres med rimelig sikkerhet, vil en av hypotesene som HUNT 2 vil kunne teste være: Vil apolipoprotein B (apoB) og apolipoprotein A-1 (apoA-1) samt ratio mellom dem, apoB/apoA-1, være like prediktive for fremtidige kardiovaskulære hendelser og død som rapportert fra utenlandske undersøkelser (3-9). I disse studiene er det påvist at apolipoproteiner kan være minst like prediktive som LDL-C og HDL-C, selv om det også finnes unntak fra dette (10). HUNT 2 vil derved kunne bli den første norske undersøkelsen som belyser dette problemområdet.

Hensikten med denne studien var å undersøke om nivåer av apolipoproteiner likner på de man finner $\mathrm{i}$ andre sammenlignbare populasjoner i utlandet, og om kjente korrelasjoner mellom apo- og lipoproteiner kan gjenfinnes også i HUNT 2-data. I tillegg ønsket vi å kontrollere om lipider og lipoprotein-nivåer har holdt seg rimelig konstante i denne 12-14-års perioden.

\section{MATERIALE OG METODER}

For å dekke formålet med denne undersøkelsen ble det tatt ut et tilfeldig utvalg på 300 personer med nedfros- ne blodprøver. Disse ble hentet fra prøver som opprinnelig var overført til Aker Sykehus, Hormonlaboratoriet, for analyse av ulike hormoner og de ble oppbevart der, nedfrosset til $-40{ }^{\circ} \mathrm{C}$. I 2008 ble disse blodprøvene overført til HUNT biobank i Levanger. For å analysere apolipoproteiner i dette prosjektet ble de 300 blodprøvene deretter transportert til Sentrallaboratoriet, St Olavs Hospital, Trondheim. Her ble de tint opp og analysert med hensyn til TC, HDL-C og TG. LDL-C ble beregnet etter Friedewalds formel (11) og standardmetoder ble benyttet (Roche/Hitachi enzymatisk kolorimetriske tester). Apo B og apoA-1 ble målt med turbidimetriske metoder. Resultatene av målingene for disse 300 personene ble overført til HUNT forskningssenter i Verdal, hvor laboratorieverdiene (TC, HDL-C og TG) som ble målt da prøvene var ferske, dvs. i 1995-97, ble påkoblet filen, i tillegg til alder og kjønn (3). Under gjennomføringen av HUNT 2 ble de ferske prøvene fortløpende analysert ved Sentrallaboratoriet, Sykehuset Levanger. Det ble brukt en Hitachi 911 Autoanalyzer (Hitachi, Mito, Japan) ved bruk av reagenser fra Boehringer Mannheim (Mannheim, Tyskland) og det ble brukt Seronorm Lipoprotein fra Nycomed Pharma AS til 2-punkts kalibrering av lipoprotein-analysene. TC og HDL ble målt ved hjelp av en enzymatisk kolorimetrisk cholesterolesterasemetode, og HDL ble målt etter presipitering med fosfortungsten og magnesiumioner. TG ble også målt med en enzymatisk kolorimetrisk metode. Dag-til-dagkoeffisientene varierte med $1,3-1,9 \%$ for TC, $2,4 \%$ for HDL og $0,7-1,3 \%$ for TG (3). Da noen personer hadde TG-verdier over 4,5 mmol/l, kunne ikke Friedewalds formel benyttes og derfor har en kun komplette datasett for 292 personer.

\section{Statistikk}

Beskrivende statistikk er brukt med gjennomsnitt, standardavvik, standardfeil og kjønnsjusterte korrelasjonskoeffisienter som angitte størrelser. Regresjonsanalyse av apolipoproteiner mot alder og mot noen andre lipoproteiner er også blitt utført for å justere for forskjeller sammenlignet med Apolipoprotein MOrtality RIsk (AMORIS), en stor svensk populasjonsstudie av apolipoproteiner (3). 
Tabell 1. Gjennomsnitt (SD) av HUNT 2 lipoproteinkomponenter etter kjønn målt i 1995-97 og etter frysing ved $-40{ }^{\circ} \mathrm{C}$ til $2009(n=292)$.

\begin{tabular}{lcccccc}
\hline & \multicolumn{3}{c}{ Målinger i 1995-97 } & \multicolumn{3}{c}{ Målinger etter frysing i 2009 } \\
Lipoproteinkomponent & Menn & Kvinner & Totalt & Menn & Kvinner & Totalt \\
\hline Total kolesterol (mmol/L) & $6,22(1,06)$ & $6,24(1,37)$ & $6,23(1,27)$ & $6,47(1,17)$ & $6,55(1,46)$ & $6,52(1,37)$ \\
LDL-kolesterol (mmol/L) & $4,04(0,98)$ & $3,98(1,20)$ & $4,00(1,13)$ & $4,54(1,12)$ & $4,54(1,32)$ & $4,54(1,26)$ \\
Non-HDL-kolesterol (mmol/L) & $5,07(1,11)$ & $4,78(1,37)$ & $4,88(1,29)$ & $5,54(1,18)$ & $5,36(1,49)$ & $5,42(1,39)$ \\
HDL-kolesterol (mmol/L) & $1,22(0,33)$ & $1,47(0,40)$ & $1,38(0,39)$ & $0,99(0,29)$ & $1,19(0,34)$ & $1,12(0,34)$ \\
Triglyserider (mmol/L) & $2,09(0,97)$ & $1,75(0,90)$ & $1,87(0,94)$ & $2,09(0,85)$ & $1,82(0,90)$ & $1,91(0,89)$ \\
Apolipoprotein B (g/L) & - & - & - & $1,29(0,28)$ & $1,22(0,33)$ & $1,24(0,32)$ \\
Apolipoprotein A1 (g/L) & - & - & - & $1,59(0,29)$ & $1,74(0,31)$ & $1,69(0,31)$ \\
Total kol/HDL-kol & $5,44(1,62)$ & $4,54(1,56)$ & $4,85(1,63)$ & $7,04(2,36)$ & $5,99(2,39)$ & $6,35(2,43)$ \\
ApoB/apoA-1 & - & - & - & $0,84(0,25)$ & $0,72(0,24)$ & $0,76(0,25)$ \\
\hline
\end{tabular}

$\mathrm{SD}=$ standarddeviasjon; $\mathrm{LDL}=$ low density lipoprotein; $\mathrm{HDL}=$ high density lipoprotein, Non-HDL-kolesterol = total kolesterol minus HDL-kolesterol

\section{Etikk og personvern}

Prøvene som ble brukt i denne studien ble tilfeldig plukket ut fra HUNT biobank, de var fullstendig anonymisert, dvs. at all personidentifikasjon og løpenummer ble slettet, og svært få variable ble inkludert. Etter som personidentifikasjon derfor ikke var mulig, ble det ikke søkt REK for dette prosjektet.

\section{RESUlTATER}

Sammenlikning av måleverdier av lipoproteinkomponenter (LK) i 1995-97 og opptinte prøver etter frysing til 2009 er vist i Tabell 1, oppdelt etter kjønn. TC var blitt forhøyet med ca. 0,3 mmol/L, mens LDL-C og non-HDL-C var blitt forhøyet med ca. $0,5 \mathrm{mmol} / \mathrm{L}$. Triglyserid nivået forble omtrent uforandret. HDL-C sank med ca. 0,25 mmol/L i dette tidsrommet. Ratio mellom TC og HDL-C økte med ca. 30\%, hovedsakelig grunnet reduserte HDL-C verdier. Variasjonsmønsteret $\mathrm{i}$ endringene er gitt $\mathrm{i}$ Tabell 2.

For å undersøke om de sammenhengene som finnes mellom LK ved direkte målinger (evt. indirekte etter beregninger) ble gjenfunnet også for de tinte prøvene etter 12 års nedfrysing, er kjønnsjusterte partielle korrelasjonskoeffisienter mellom alle målinger og beregninger vist i Tabell 3. Korrelasjonen mellom direkte målte og opptinte verdier av TC var 0,96 og det samme gjaldt for LDL-C. Nesten like høye korrelasjoner ble funnet for HDL-C $(\mathrm{r}=0,93)$. For triglyserider var korrelasjonen 0,99 . Slike korrelasjoner kan imidlertid være et resultat av stor spredning i nivå mellom deltakerne og derfor ble noen variasjonskoeffisienter beregnet (SD av endring/gjennomsnittsnivå). Disse var $5,8 \%$ for TC, $13,7 \%$ for HDL-C, $8,1 \%$ for beregnet LDL-C, 9,0\% for triglyserider og 20,1\% for TC/HDL$\mathrm{C}$ ratio. Bortsett fra TC ligger disse koeffisienter vesentlig høyere enn de man vanligvis beregner ved dobbeltmålinger (alle vanligvis under 5\%). Det ble også påvist at forskjellene i total-kolesterol var relatert til gjennomsnittsnivået av TC ved at differensen steg
Tabell 2. Økning i HUNT 2 lipoproteinmålinger fra 1995/97 til opptinte målinger i 2009.

\begin{tabular}{lccc}
\hline Differanser & Gjennomsnitt & SD & Variasjonsbredde \\
\hline TC $(\mathrm{mmol} / \mathrm{L})$ & 0,28 & 0,37 & $-1,20-1,80$ \\
LDL $(\mathrm{mmol} / \mathrm{L})$ & $-0,53$ & 0,34 & $-1,79-0,52$ \\
HDL (mmol/L) & $-0,26$ & 0,14 & $-0,98-0,07$ \\
TG (mmol/L) & 0,04 & 0,17 & $-1,09-0,56$ \\
TC/HDL & 1,54 & 1,13 & $0,05-8,89$ \\
Non-HDL (mmol/L) & 0,54 & 0,38 & $-1,01-1,99$ \\
\hline
\end{tabular}

$\mathrm{LDL}=$ low density lipoprotein kolesterol; HDL $=$ high density lipoprotein kolesterol; TG $=$ triglyserider; Non-HDL = total kolesterol minus HDL

med 0,069 (SE 0,016) $\mathrm{mmol} / \mathrm{L}$ pr mmol/L økning i nivå. For beregnet LDL-C var tilsvarende tall 0,101 $(0,016)$, for HDL-C $-0,149(0,022)$ og for triglyserider $-0,046(0,009)$. Dette tyder på at de endringer som fant sted ikke var homogene, men heller avhengige av det nivået målingene hadde.

\section{Nivå av apolipoproteiner}

Hovedhensikten med denne studien var å kartlegge om målinger av apolipoproteiner i HUNT 2 etter 12-14 års nedfrysing kunne brukes som prediktorer i epidemiologiske studier. Det var derfor vesentlig både å få karlagt om disse målingene hadde nivåer som virket rimelige, og om de hadde korrelasjoner med lipoproteiner som harmonerte med andres funn. I tabell $1 \mathrm{er}$ angitt gjennomsnittsnivåer for apoB, apoA-1 og ratio apoB/apoA-1. Nivåene for $\mathrm{apoB}$ og apoA-1 virker høye og spesielt virker apoA-1 å være høyere enn hva man finner $i$ andre populasjoner. ApoB/apoA-1 derimot ligger plassert passende med en frisk middelaldrende populasjon (3). Fra Tabell 2 kan en se at korrelasjonene mellom apoB og lipoproteiner er som forventet: LDL-C etter nedfrysing korrelerer svært høyt $(\mathrm{r}=0,90)$ og at apoB korrelerer negativt med HDL-C er også vel kjent (9). 
Tabell 3. Kjønnsjusterte partielle korrelasjonskoeffisienter mellom ferske LK målinger i HUNT 2 (1995-97) og etter frysing ved $-40^{\circ} \mathrm{C}$ til $2009(\mathrm{n}=292)$

\begin{tabular}{|c|c|c|c|c|c|c|c|c|c|c|c|c|}
\hline \multirow[b]{2}{*}{ Ferske målinger } & \multicolumn{4}{|c|}{ Ferske prøver } & \multicolumn{8}{|c|}{ Målinger etter nedfrysing til 2009} \\
\hline & $\mathrm{TC}$ & LDL & HDL & TG & $\mathrm{TC}$ & LDL & HDL & $\mathrm{TG}$ & ApoB & ApoA1 & $\begin{array}{c}\mathrm{TC} / \\
\mathrm{HDL} \\
\end{array}$ & $\begin{array}{c}\text { ApoB/ } \\
\text { A1 }\end{array}$ \\
\hline TC & 1 & & & & & & & & & & & \\
\hline LDL & 0,93 & 1 & & & & & & & & & & \\
\hline HDL & 0,10 & $-0,03$ & 1 & & & & & & & & & \\
\hline TG & 0,37 & 0,14 & $-0,44$ & 1 & & & & & & & & \\
\hline \multicolumn{13}{|l|}{2009} \\
\hline $\mathrm{TC}$ & 0,96 & 0,92 & 0,17 & 0,27 & 1 & & & & & & & \\
\hline LDL & 0,93 & 0,96 & 0,09 & 0,13 & 0,97 & 1 & & & & & & \\
\hline HDL & $-0,03$ & $-0,13$ & 0,93 & $-0,57$ & 0,06 & $-0,02$ & 1 & & & & & \\
\hline TG & 0,39 & 0,22 & $-0,44$ & 0,99 & 0,33 & 0,18 & $-0,56$ & 1 & & & & \\
\hline ApoB & 0,88 & 0,89 & $-0,17$ & 0,42 & 0,90 & 0,90 & $-0,28$ & 0,47 & 1 & & & \\
\hline ApoA-1 & 0,26 & 0,08 & 0,83 & $-0,19$ & 0,34 & 0,22 & 0,80 & $-0,16$ & 0,01 & 1 & & \\
\hline $\mathrm{TC} / \mathrm{HDL}$ & 0,61 & 0,63 & $-0,59$ & 0,66 & 0,55 & 0,57 & $-0,73$ & 0,68 & 0,77 & $-0,43$ & 1 & \\
\hline ApoB/A1 & 0,59 & 0,68 & $-0,57$ & 0,46 & 0,55 & 0,61 & $-0,65$ & 0,49 & 0,80 & $-0,53$ & 0,90 & 1 \\
\hline
\end{tabular}

$\mathrm{LK}=$ lipoprotein komponenter; $\mathrm{TC}=$ total kolesterol; $\mathrm{LDL}=$ low density lipoprotein kolesterol; $\mathrm{HDL}=$ high density lipoprotein kolesterol; $\mathrm{TG}=$ triglyserider; $\mathrm{ApoB}=$ apolipoprotein $\mathrm{B}, \mathrm{ApoA} 1=$ apolipoprotein $\mathrm{A}-1$

Tabell 4. Sammenlikning av kjønnsspesifikke gjennomsnittlige (SD) lipider og apolipoproteinnivåer i HUNT 2 med de målt i AMORIS studien i perioden 1985-96, justert til samme alder.*

\begin{tabular}{lcccc}
\hline & \multicolumn{2}{c}{ HUNT 2, målt i 2009 } & \multicolumn{2}{c}{ AMORIS direkte målt } \\
Komponenter & Menn & Kvinner & Menn & Kvinner \\
\hline ApoB I $(\mathrm{g} / \mathrm{L})$ & $1,35(0,28)$ & $1,26(0,33)$ & $1,33(0,33)$ & $1,25(0,35)$ \\
ApoA1 $(\mathrm{g} / \mathrm{L}) \S$ & $1,40(0,29)$ & $1,54(0,31)$ & $1,37(0,20)$ & $1,50(0,23)$ \\
ApoB/apoA1§ & $0,88(0,25)$ & $0,78(0,25)$ & $1,00(0,239)$ & $0,85(0,28)$ \\
TC $(\mathrm{mmol} / \mathrm{L})$ & $5,95(1,06)$ & $6,09(1,37)$ & $6,00(1,11)$ & $6,08(1,22)$ \\
TG $(\mathrm{mmol} / \mathrm{L})$ & $1,99(0,97)$ & $1,69(0,90)$ & $1,54(0,83)$ & $1,23(0,70)$ \\
\hline
\end{tabular}

$\mathrm{SD}=$ standardavvik; AMORIS $=$ Apolipoprotein MOrtality RISk Study; ApoB = apolipoprotein B; ApoA 1= apolipoprotein A-1; TC = total kolesterol; TG = triglyserider

* Justering utført ved lineær regresjon mellom alder og HUNT 2 målt i 2009

$\S$ Justert apoA-1 etter lineær regresjon med HDL- kolesterol målt i HUNT 2 i 2009

AMORIS-studien, hvor ca. 150,000 menn og kvinner $\mathrm{i}$ alle aldre fikk målt TC, triglyserider, apoB og apoA-1 direkte, er her blitt brukt som sammenlikningsgrunnlag. Dette på grunn av materialets størrelse og at det kan tjene som normalmateriale for svenske forhold for 15-25 år siden, altså noe før HUNT 2 ble gjennomført. Sammenlikninger av AMORIS med andre studier viser imidlertid stor grad av samsvar hva distribusjoner angår (3). Da apoB og andre variable er avhengig av alder, og AMORIS-populasjonen er 7 og 4 år yngre enn i HUNT 2 (menn og kvinner henholdsvis), er HUNT 2 resultatene justert etter de aldersregresjoner som ble funnet for hver variabel. I tillegg er det laget en regresjonsjustering for apoA-1 nivået ved hjelp av tint HDL-C nivå, siden HDL-C ved de to tidspunkt for HUNT 2 var vesentlig ulike. Denne justeringen alene stod for en generell reduksjon av apoA-1 på ca. 0,2 $\mathrm{g} / \mathrm{L}$. Tabell 4 viser at etter disse justeringer ble nivåene av apolipoproteinene i HUNT 2 og AMORIS sammenliknbare. Også TC var like, mens triglyserider var vesentlig lavere i AMORIS enn i HUNT 2. Dette kan være et reelt funn, men er noe vanskelig å vurdere da AMORIS ikke samlet inn opplysninger om andre livsstilsrelaterte faktorer som livvidde, røykevaner etc. Fedmeepidemien var også kommet ulikt langt i sin europeiske utbredelse $\mathrm{i}$ de to tidsperioder hvor datainnsamlingene fant sted.

\section{DISKUSJON}

Ujusterte apolipoproteinnivåer lå på et høyt nivå, det gjaldt både apoB og apoA-1. Til sammenlikningsgrunnlag brukte vi AMORIS data, hentet inn fra ikkehospitaliserte friske deltakere ved helsekontroller i perioden 1985-96, hovedsakelig fra Stockholmsområdet i Sverige. Aldersjusteringer ble foretatt, men kun ved å bruke HDL-C verdier fra opptinte blodprøver, ble det mulig å justere verdiene på apoA-1 slik at de harmonerte med nivåene i AMORIS og nivå som ellers er rapportert $(8,10)$. Skal apoB og apoA-1 verdier samt 
deres ratio benyttes som prediktorer for fremtidige kardiovaskulære hendelser og dødsfall, er det imidlertid tvilsomt om justerte apolipoproteinverdier bør benyttes. Vi vet bare at gjennomsnittsnivåene trolig blir mer plausible ved en slik justering, mens relasjonenes styrke kan endres vesentlig ved at apoA-1 justeres for HDL-C nivå, grunnet deres høye interkorrelasjon. Dette vil imidlertid kunne undersøkes nøyere hvis prediksjonsstudier blir gjennomført.

Relasjonene mellom apo- og lipoproteiner var stort sett som en skulle vente ut fra andre studier (3), dvs. resultater både fra populasjonsstudier av friske individer og fra statin-behandlede populasjoner med hjerte/karsykdom (12) hvor målingene ble foretatt på ferske prøver.

Det er forbausende at forskjellene i nivåer på flere direkte målte variable er blitt vesentlig endret etter nedfrysing i 12-14 år. TC er blitt klart forøket, mens HDL-C har fått reduserte nivåer. En av årsakene til dette kan være at på Aker sykehus ble blodprøvene bare frosset ned til $-40{ }^{\circ} \mathrm{C}$, mens resten av HUNT 2 prøvene er lagret ved $-80{ }^{\circ} \mathrm{C}$. Det er vel kjent at ved lang tids lagring kan HDL lipoprotein-partiklene aggregere med seg selv eller med andre lipoproteinpartikler, slik at de i noen grad ko-presipiteres med VLDL og LDL lipoprotein-partiklene. Derved kan HDL-C nivåene bli lavere. At reduksjonen øker med økende nivå er noe uventet, men kan tenkes å skyldes at jo tettere HDL-partiklene ligger lagret, desto lettere dannes det komplekser som kan felles etter lagring i mange år. Dess høyere temperaturen er, dess mer vil slik aktivitet kunne finne sted. Da hovedmassen av blodprøver i HUNT 2 er frosset til $-80^{\circ} \mathrm{C}$ og ellers er blitt liggende i ro, er det grunn til å tro at slike endringer som her er funnet vil bli klart mindre i denne.

Teoretisk sett skulle ikke nivåene på TC endres etter slik lagring. At vi her finner at TC er blitt forøket, kan skyldes at endringer i målemetode og/eller målerutiner har funnet sted i denne perioden, men i begge tilfeller skulle metodene være kalibrerte mot samme standarder. Å rette opp for disse endringer kan være noe vanskelig, da de synes å være nivåavhengige.

En begrensning i analysene er at lineær regresjonsanalyse er blitt benyttet til justering for alder. I den grad sammenhengene er ikke-lineære, kan de justerte estimater være gjenstand for residual konfundering.

\section{KONKLUSJONER}

Etter justeringer for alder og bruk av opptint HDLkolesterolnivå, tyder mye på at apolipoproteinmålingene burde kunne benyttes som grunnlag for nivåmålinger, mens analyser av prediktivitet $i$ langtids prospektive oppfølgningsstudier mht. sykelighet og dødelighet i HUNT 2 kunne blitt mer problematiske hvis frosne prøver til $-40{ }^{\circ} \mathrm{C}$ skulle tines opp. Likevel er det grunn til å tro at de økte verdiene av TC som ble funnet etter lagring ved $-40{ }^{\circ} \mathrm{C}$ i $12-14$ år og andre uregelmessigheter ikke vil finne sted for hovedmassen av HUNT 2 blodprøver, da HUNT biobank har frosset prøvene til $-80^{\circ} \mathrm{C}$ og ellers ikke er blitt tint opp. Prospektive kliniske endepunktsanalyser med apolipoproteiner som risikofaktorer burde derfor kunne utføres med HUNT 2-data. Imidlertid, dette vil man først kunne vite når slike tinte blodprøver blir analysert.

\section{TIL ERKJENTLIGHET}

Forfatterne ønsker å takke Det medisinske fakultet, NTNU, Nord Trøndelag fylkeskommune og Nasjonalt Folkehelseinstitutt for anledningen til å benytte HUNT-2 data til utarbeidelsen av denne artikkelen.

\section{REFERANSER}

1. Musigavon P, Yipintsoi T. Loss of high density lipoprotein cholesterol in serum: effect of storage. $J$ Med Assoc Tai 2005; 88: 1388-94.

2. Holmen J, Midthjell K, Kruger O, Langhammer A, Holmen TL, Bratberg GH, Vatten L, Lund-Larsen PG. The Nord-Trøndelag Health Study 1995-97 (HUNT 2): Objectives, contents, methods and participation. Norsk Epidemiologi 2003; 13: 19-22.

3. Jungner I, Marcovina SM, Walldius G, Holme I, Kolar W, Steiner E. Apolipoprotein B and A-1 values in 147576 Swedish males and females, standardized according to the World Health Organization-International Federation of Clinical Chemistry First International Reference Materials. Clin Chem 1998; 44: 1641-9.

4. Walldius G, Jungner I, Holme I, Aastveit AH, Kolar W, Steiner E. High apolipoprotein B, low lipoprotein A1 , and improvement in the prediction of fatal myocardial infarction (AMORIS study): a prospective study. Lancet 2001; 358: 2026-33.

5. Holme I, Aastveit AH, Jungner I, Walldius G. Relationships between lipoprotein components and risk of myocardial infarction: age, gender and short versus longer follow-up periods in the Apolipoprotein MOrtality RIsk study (AMORIS). J Intern Med 2008; 264: 30-8.

6. Holme I, Aastveit AH, Hammar N, Jungner I, Walldius G. Relationships between lipoprotein components and risk of ischaemic and haemorrhagic stroke in the Apolipoprotein MOrtality RIsk study (AMORIS). $J$ Intern Med 2009; 265: 275-87. 
7. Walldius G, Jungner I. The apoB/apoA-1 ratio: a strong, new risk factor for cardiovascular disease and a target for lipid-lowering therapy - a review of the evidence. J Intern Med 2006; 259: 493-519.

8. McQueen MJ, Hawken S, Wang X, et al., for the INTERHEART study investigators. Lipids, lipoproteins, and apolipoproteins as risk markers of myocardial infarction in 52 countries (the INTERHEART study): a case control study. Lancet 2008; 372: 224-33.

9. Parish S, Peto R, Palmer A, et al. The joint effects of apolipoprotein B, apolipoprotein A1, LDL cholesterol and HDL cholesterol on risk: 3510 cases of acute myocardial infarction and 9805 controls. Eur Heart J 2009: 30: $2137-46$.

10. Ingelsson E, Schaefer EJ, Contois JH, et al. Clinical utility of different lipid measures for prediction of coronary heart disease in men and women. JAMA 2007; 298: 776-85.

11. Friedewald WT, Levy RL, Fredrickson DS. Estimation of the concentration of low-density lipoprotein cholesterol in plasma, without use of the preparative ultricentrifuge. Clin Chem 1972; 18: 499-502.

12. Holme I, Cater NB, Faergeman O et al. On behalf of the Incremental Decrease in End-Points Through Aggressive Lipid-lowering Study group. Lipoproteon predictors of cardiovascular events in statin-treated patients with coronary heart disease. Insights from the Incremental Decrease in End-Points through Aggressive Lipidlowering Trial (IDEAL). Ann Med 2008; 40: 456-64. 